•研究报告・

\title{
中国大型担子菌受威胁现状评估
}

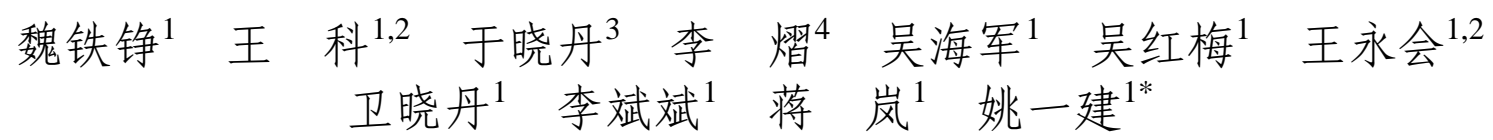

1 (中国科学院微生物研究所真菌学国家重点实验室, 北京 100101)

2 (中国科学院大学, 北京 100049)

3 (沈阳农业大学生物科学技术学院, 沈阳 110866)

4 (扬州大学食品科学与工程学院, 江苏扬州 225127)

摘要: 基于文献和标本信息以及专家提供的数据, 依据中国大型真菌评估的标准和程序, 对中国范围内已知大型 担子菌进行了受威胁状态评估。结果显示, 在评估的6,268种担子菌中, 受威胁(疑似灭绝、极危、濒危、易危)的 物种有 45 种, 受威胁比例为 $0.72 \%$ 。受威胁的大型担子菌物种中食药用菌比例达 $1 / 3$ 以上，且大部分物种仍无法人 工栽培, 主要依赖野生资源。我国受威胁担子菌主要集中分布在西南和东北地区。人类活动导致的物种栖息地萎 缩和破坏是我国大型担子菌受威胁的首要因子, 过度采挖是食药用菌受威胁的重要原因。此外, 数据不足的大型 担子菌共 4,251 种, 占被评估大型担子菌总数的 $67.82 \%$, 表明我国大型担子菌物种多样性及相关研究还存在不足。 关键词：真菌; 红色名录; 受威胁物种; 食药用菌

\section{Assessment of the threatened status of macro-basidiomycetes in China}

Tiezheng $\mathrm{Wei}^{1}$, Ke Wang ${ }^{1,2}$, Xiaodan $\mathrm{Yu}^{3}$, Yi $\mathrm{Li}^{4}$, Haijun $\mathrm{Wu}^{1}$, Hongmei $\mathrm{Wu}^{1}$, Yonghui Wang ${ }^{1,2}$, Xiaodan $\mathrm{Wei}^{1}$, Binbin $\mathrm{Li}^{1}$, Lan Jiang ${ }^{1}$, Yijian $\mathrm{Yao}^{{ }^{*}}$

1 State Key Laboratory of Mycology, Institute of Microbiology, Chinese Academy of Sciences, Beijing 100101

2 University of Chinese Academy of Sciences, Beijing 100049

3 Colloge of Bioscience and Biotechnology, Shenyang Agricultural University, Shenyang 110866

4 School of Food Science and Engineering, Yangzhou University, Yangzhou, Jiangsu 225127

Abstract: A red list assessment of macrofungi was performed to determine the threatened status of known macro-basidiomycetes in China. Forty-five species were considered threatened, with species classified as either Possibly Extinct (PE), Critically Endangered (CR), Endangered (EN) or Vulnerable (VU). These species account for $0.72 \%$ of the 6,268 macro-basidiomycete species. More than one-third of the threatened species are edible or medicinal fungi, and most of them are uncultivable, meaning they only grow in the wild. The threatened basidiomycete species are mainly distributed across Southwest and Northeast China. The main threats to these species are shrinking and destruction of habitat caused by human activities, although excessive picking is a major threat for the edible and medicinal species. However, there were insufficient data for 4,251 macro-basidiomycetes species, $67.82 \%$ of all species, which suggests that this red list assessment is incomplete.

Key words: fungi; red list; threatened species; edible or medicinal fungi

担子菌是有性生殖在称为担子的产孢结构上 形成外生担孢子(basidiospores)的一类真菌的统称 (Alexopoulos et al, 1996)。Catalogue of Life (http:// www.catalogueoflife.org/col/info/totals, 截至2019年
6月20日)已收录全球担子菌门真菌超过4.8万种, 它 们是物种数量仅次于子囊菌门的真菌第二大类群。 担子菌中的大多数种类具有肉眼可见的子实体, 目 前已发现的大型真菌绝大多数属于担子菌(Mueller

收稿日期: 2019-05-14; 接受日期: 2019-07-09

基金项目: 生态环境部生物多样性调查评估项目(2019HJ2096001006)

* 通讯作者 Author for correspondence. E-mail: yaoyj@im.ac.cn 
et al, 2007)。大型担子菌分布极为广泛, 生物量巨大, 与动植物形成密不可分的关系, 在自然生态系统中 发挥着重要的作用。大型担子菌中的许多类群, 如 我高属(Amanita)、牛肝菌属(Boletus)、口蘑属(Tricholoma) 等, 能与树木形成外生菌根, 与宿主植物之 间建立互惠共生关系(Singer, 1986)。多孔菌属(Polyporus)等木材腐朽菌在森林系统的物质循环中具 有重要作用。大型担子菌与人类的生产生活关系密 切, 双孢蘑菇(Agaricus bisporus)、美味牛肝菌(Boletus edulis)、蚁巢伞(Termitomyces spp.)等重要食用 菌, 灵芝(Ganoderma sichuanense)、茯苓(Wolfiporia cocos)、牛樟芝(Taiwanofungus camphoratus)等药用 菌, 以及鸡油菌(Cantharellus cibarius)、猴头菇(Hericium erinaceum)、松口蘑(Tricholoma matsutake)等 食药两用真菌在食用菌产业和医疗保健等领域发 挥着日益重要的作用。除有益作用外, 致命鹅膏 (Amanita exitialis)、裸盖菇(Psilocybe spp.)等一些有 毒的大型担子菌还威胁着人类的生命安全。

我国大型担子菌资源十分丰富, 其中不乏重要 的食药用种类。迄今为止, 国内已报道的野生食药 用大型担子菌超过 1,600 种, 占我国全部大型食药 用真菌的约93\% (Fang et al, 2018), 食药用菌产业 在我国农业中占据日益突出的地位。然而, 相对于 其丰富的物种多样性, 我国大型真菌资源保护工作 存在严重不足, 物种受威胁程度评估近年来才刚刚 起步。开展大型真菌红色名录评估, 是我国生物多 样性保护的重要工作内容。2018年5月, 国家生态环 境部(原环境保护部)和中国科学院共同发布了我国 第一部大型真菌红色名录。本文报道该名录中大型 担子菌的评估结果及分析, 以期推进我国真菌多样 性保护的相关工作。

\section{国内外担子菌受威胁状态评估现状}

欧洲是最早运用世界自然保护联盟(International Union For Conservation of Nature, IUCN)红色 名录评估方法开展大型真菌红色名录评估的地区, 已有多个国家制定了大型真菌保护的计划政策和 法律法规, 有的国家还建立了大型真菌保护地。全 世界最早的菌物红色名录由前民主德国于1982年 公布。乌克兰在其第二版植物红色名录中加入了真 菌的受威胁类群, 包含了 26 个担子菌物种 (Senn-Irlet et al, 2007)。保加利亚发布的首版大型真
菌红色名录中包含了106种大型担子菌(Gyosheva et al, 2000)。意大利首先完成了本国担子菌的物种名 录, 并以此为基础提出了933 稀有或受威胁的担子 菌类群(Senn-Irlet et al, 2007)。目前, 已经有31个欧 洲国家发布了各自的红色名录，57\%的国家对其公 布的红色名录进行过修订和再版(Senn-Irlet et al, 2007)。欧洲完善的菌物红色名录编研工作主要得益 于其雄厚的菌物分类与系统学研究基础、丰富的标 本储备、完善的信息平台和长期的菌物多样性监测 工作。早在1910年，荷兰就已经开始大型真菌的监 测工作。英国菌物红色名录是依据自1960年以来对 遍布全国的样地长期定量监测的结果。欧洲已经建 立了较完善的菌物监测网络, 成为其菌物红色名录 最直接的数据来源。

目前, 我国还未对包括大型担子菌在内的大型 真菌进行全面、大规模的评估。已有的主要是一些 菌物学者开展的零散的评估分析，且评估体系大多 未采用IUCN等级和标准, 也缺乏全面系统的研究。 国内的大型担子菌受威胁状况评估始于2003年，刘 培贵等(2003)依据动、植物的划分方法, 将大型真菌 分为濒危类群、重大科学价值类群和重要经济类群 等3类，担子菌中的蚁巢伞属(Termitomyces)、松茸 群(Tricholoma matsutake-group)和有药用价值的多 孔菌等被划入濒危类群。戴玉成(2003)列举了长白 山森林生态系统中的稀有和濒危多孔菌27种。范宇 光和图力古尔(2008)对长白山国家级自然保护区受 威胁大型真菌物种进行量化评价，涉及大型担子菌 36 种, 其中极危 2 种、濒危 4 种、易危 10 种、近危 9 种、 无危11种。廖宇静等(2008)探讨了重庆金佛山国家 级自然保护区大型真菌多样性及资源保护与可持 续利用问题，将15种大型担子菌列为濒危。戴玉成 等(2010)发现分布于我国20个省区的48种多孔菌为 濒危物种。魏铁铮和姚一建(2010)根据世界自然保 护联盟物种红色名录等级和标准提出我国受威胁 大型真菌物种有 137 种(濒危54种，易危54种，近危 29种), 其中担子菌123种。王建瑞等(2015)采用层次 分析(analytic hierarchy process, AHP)和专家咨询相 结合的方法确定了评价层次的目标权重, 并对山东 省175种大型真菌的濒危程度和优先保育进行了评 估, 其中建议列为一级和二级保护的物种都是担子 菌的类群。21世纪以来, 我国专家学者对部分大型 真菌的受威胁状况开展了评估工作，其中涉及到部 
分大型担子菌类群。然而, 已开展的这些评估工作所 涉及的物种数量少, 而且所涉及的地理区域大多比 较狭窄, 难以反映我国大型担子菌的整体生存状况。

\section{2 评估方法及流程}

大型担子菌红色名录评估的等级和标准依据 《中国大型真菌红色名录评估方法和程序》(王科等, 2020)进行。评估等级主要包括灭绝(Extinct, EX)、 野外灭绝(Extinct in the Wild, EW)、疑似灭绝 (Possibly Extinct, PE)、极危(Critically Endangered, $\mathrm{CR}) 、$ 濒危(Endangered, EN)、易危(Vulnerable, VU)、 近危(Near Threatened, NT)、无危(Least Concern, LC)、数据不足(Data Deficient, DD)、未予评估(Not Evaluated, NE)。该标准和规范参考IUCN红色名录 评估等级标准(IUCN, 2012a, 2012b; IUCN Standards and Petitions Subcommittee, 2016), 同时结合我国大 型真菌资源现状、已有研究、开发利用及资源保护 的具体情况而制定。
大型担子菌红色名录评估过程依照中国大型 真菌红色名录评估操作程序开展, 包括初评、函评、 会评、复审、形成评估说明书 5 个步骤(王科等, 2020)。评估数据主要来源于中国菌物名录数据库 (http://www.fungalinfo.net/)和相关领域专家提供的 咨询信息。

\section{3 大型担子菌评估结果与分析}

\section{1 评估结果}

本次评估的大型担子菌共6,268种, 分属于3纲 23 目106科841属。评估物种数量最多的是蘑菇纲, 达6,158 种，占被评估大型担子菌物种总数的 $98.25 \%$; 其次为银耳纲和花耳纲，分别为56种和52 种; 此外还有未定纲 2 种。评估物种数量最多的目是 蘑菇目, 达2,926种, 占被评估大型担子菌物种总数 的 $46.68 \%$ 。评估物种数量最多的科是多孔菌科, 达 478种, 占被评估大型担子菌物种总数的 $7.63 \%$ 。我 国大型担子菌类群及受威胁状况评估结果见表1。

表1 大型担子菌评估类群及评估等级

Table 1 Assessed groups and categories of macro-basidiomycetes

\begin{tabular}{|c|c|c|c|c|c|c|}
\hline \multirow[t]{2}{*}{ 评估类群 Taxa } & \multirow{2}{*}{$\begin{array}{l}\text { 物种数 } \\
\text { No. of species }\end{array}$} & \multicolumn{5}{|c|}{ 受威胁等级及物种数 Threatened categories and number of species } \\
\hline & & $\begin{array}{l}\text { 濒危 } \\
\text { Endangered }\end{array}$ & $\begin{array}{l}\text { 易危 } \\
\text { Vulnerable }\end{array}$ & $\begin{array}{l}\text { 近危 } \\
\text { Near Threatened }\end{array}$ & $\begin{array}{l}\text { 无危 } \\
\text { Least Concern }\end{array}$ & $\begin{array}{l}\text { 数据不足 } \\
\text { Data Deficient }\end{array}$ \\
\hline 蘑菇纲 Agaricomycetes & 6,158 & 13 & 28 & 54 & 1,880 & 4,183 \\
\hline 蘑菇目 Agaricales & 2,926 & 8 & 11 & 17 & 838 & 2,052 \\
\hline 蘑菇科 Agaricaceae & 445 & 5 & 2 & 1 & 148 & 289 \\
\hline 鹅膏科 Amanitaceae & 157 & & 1 & 1 & 78 & 77 \\
\hline 粪伞科 Bolbitiaceae & 43 & & & & 14 & 29 \\
\hline 珊瑚菌科 Clavariaceae & 53 & & & & 15 & 38 \\
\hline 丝膜菌科 Cortinariaceae & 221 & 1 & 1 & & 16 & 203 \\
\hline 挂钟菌科 Cyphellaceae & 3 & & & & 3 & \\
\hline 粉褶䓥科 Entolomataceae & 224 & & 1 & & 30 & 193 \\
\hline 牛排菌科 Fistulinaceae & 5 & & & & 3 & 2 \\
\hline 轴腹菌科 Hydnangiaceae & 27 & & & 2 & 10 & 15 \\
\hline 蜡伞科 Hygrophoraceae & 99 & & & & 37 & 62 \\
\hline 腹菌科 Hymenogastraceae & 138 & & & & 32 & 106 \\
\hline 丝盖伞科 Inocybaceae & 179 & 1 & & & 46 & 132 \\
\hline 离禇伞科 Lyophyllaceae & 64 & & 2 & 5 & 19 & 38 \\
\hline 小皮伞科 Marasmiaceae & 184 & 1 & & & 50 & 133 \\
\hline 小菇科 Mycenaceae & 147 & & & & 33 & 114 \\
\hline 类脐菇科 Omphalotaceae & 96 & & & & 22 & 74 \\
\hline 歧裂灰包科 Phelloriniaceae & 2 & & & & 1 & 1 \\
\hline
\end{tabular}




\section{表1 (续) Table 1 (continued)}

\begin{tabular}{|c|c|c|c|c|c|c|}
\hline \multirow[t]{2}{*}{ 评估类群 Taxa } & \multirow{2}{*}{$\begin{array}{l}\text { 物种数 } \\
\text { No. of species }\end{array}$} & \multicolumn{5}{|c|}{ 受威胁等级及物种数 Threatened categories and number of species } \\
\hline & & $\begin{array}{l}\text { 濒危 } \\
\text { Endangered }\end{array}$ & $\begin{array}{l}\text { 易危 } \\
\text { Vulnerable }\end{array}$ & $\begin{array}{l}\text { 近危 } \\
\text { Near Threatened }\end{array}$ & $\begin{array}{l}\text { 无危 } \\
\text { Least Concern }\end{array}$ & $\begin{array}{l}\text { 数据不足 } \\
\text { Data Deficient }\end{array}$ \\
\hline 泡头菌科 Physalacriaceae & 67 & & & 1 & 20 & 46 \\
\hline 侧耳科 Pleurotaceae & 66 & & & 3 & 19 & 44 \\
\hline 光柄菇科 Pluteaceae & 69 & & 1 & & 22 & 46 \\
\hline 皮孔菌科 Porotheleaceae & 4 & & & & 2 & 2 \\
\hline 小脆柄菇科 Psathyrellaceae & 116 & & & & 25 & 91 \\
\hline 羽瑚菌科 Pterulaceae & 19 & & & & 2 & 17 \\
\hline 裂褶菌科 Schizophyllaceae & 3 & & & & 1 & 2 \\
\hline 球盖菇科 Strophariaceae & 158 & & & 2 & 85 & 71 \\
\hline 口蘑科 Tricholomataceae & 284 & & 2 & 2 & 85 & 195 \\
\hline 假脐菇科 Tubariaceae & 4 & & & & & 4 \\
\hline 核瑚菌科 Typhulaceae & 11 & & & & & 11 \\
\hline 未定科 Incertae sedis & 38 & & 1 & & 20 & 17 \\
\hline 淀粉伏革菌目 Amylocorticiales & 10 & & & & 4 & 6 \\
\hline 淀粉伏革菌科 Amylocorticiaceae & 10 & & & & 4 & 6 \\
\hline 木耳目 Auriculariales & 72 & & & & 30 & 42 \\
\hline 木耳科 Auriculariaceae & 57 & & & & 25 & 32 \\
\hline 未定科 Incertae sedis & 15 & & & & 5 & 10 \\
\hline 牛肝菌目 Boletales & 562 & 1 & 5 & 4 & 209 & 343 \\
\hline 牛肝菌科 Boletaceae & 390 & & 2 & 2 & 129 & 257 \\
\hline 禇孔牛肝菌科 Boletinellaceae & 5 & & & & 2 & 3 \\
\hline 丽口包科 Calostomataceae & 16 & 1 & 2 & & 3 & 10 \\
\hline 粉孢革菌科 Coniophoraceae & 5 & & & & 2 & 3 \\
\hline 双被地星科 Diplocystidiaceae & 3 & & & & 2 & 1 \\
\hline 腹狍菌科 Gastrosporiaceae & 1 & & & & & 1 \\
\hline 铆钉菇科 Gomphidiaceae & 16 & & & 2 & 8 & 6 \\
\hline 圆孔牛肝菌科 Gyroporaceae & 12 & & & & 6 & 6 \\
\hline 拟蜡伞科 Hygrophoropsidaceae & 2 & & & & 1 & 1 \\
\hline 桩菇科 Paxillaceae & 25 & & 1 & & 7 & 17 \\
\hline 须腹菌科 Rhizopogonaceae & 10 & & & & 6 & 4 \\
\hline 硬皮马勃科 Sclerodermataceae & 20 & & & & 9 & 11 \\
\hline 硬皮腹菌科 Sclerogastraceae & 2 & & & & & 2 \\
\hline 干腐菌科 Serpulaceae & 4 & & & & 3 & 1 \\
\hline 乳牛肝菌科 Suillaceae & 45 & & & & 27 & 18 \\
\hline 小塔氏菌科 Tapinellaceae & 6 & & & & 4 & 2 \\
\hline 鸡油菌目 Cantharellales & 56 & & 1 & 2 & 17 & 36 \\
\hline 滑瑚菌科 Aphelariaceae & 3 & & & & 1 & 2 \\
\hline 鸡油菌科 Cantharellaceae & 33 & & 1 & 2 & 12 & 18 \\
\hline 锁瑚菌科 Clavulinaceae & 10 & & & & 3 & 7 \\
\hline 齿菌科 Hydnaceae & 9 & & & & 1 & 8 \\
\hline 胶膜菌科 Tulasnellaceae & 1 & & & & & 1 \\
\hline 伏革菌目 Corticiales & 26 & & & & 4 & 22 \\
\hline 伏革菌科 Corticiaceae & 26 & & & & 4 & 22 \\
\hline
\end{tabular}


表1 (续) Table 1 (continued)

\begin{tabular}{|c|c|c|c|c|c|c|}
\hline \multirow[t]{2}{*}{ 评估类群 Taxa } & \multirow{2}{*}{$\begin{array}{l}\text { 物种数 } \\
\text { No. of species }\end{array}$} & \multicolumn{5}{|c|}{ 受威胁等级及物种数 Threatened categories and number of species } \\
\hline & & $\begin{array}{l}\text { 濒危 } \\
\text { Endangered }\end{array}$ & $\begin{array}{l}\text { 易危 } \\
\text { Vulnerable }\end{array}$ & $\begin{array}{l}\text { 近危 } \\
\text { Near Threatened }\end{array}$ & $\begin{array}{l}\text { 无危 } \\
\text { Least Concern }\end{array}$ & $\begin{array}{l}\text { 数据不足 } \\
\text { Data Deficient }\end{array}$ \\
\hline 地星目 Geastrales & 25 & & & & 15 & 10 \\
\hline 地星科 Geastraceae & 25 & & & & 15 & 10 \\
\hline 粘褶菌目 Gloeophyllales & 18 & & & 1 & 8 & 9 \\
\hline 粘褶菌科 Gloeophyllaceae & 18 & & & 1 & 8 & 9 \\
\hline 钉菇目 Gomphales & 140 & & 5 & 17 & 41 & 77 \\
\hline 棒瑚菌科 Clavariadelphaceae & 9 & & & & 4 & 5 \\
\hline 钉菇科 Gomphaceae & 125 & & 5 & 17 & 37 & 66 \\
\hline 木瑚菌科 Lentariaceae & 6 & & & & & 6 \\
\hline 刺革菌目 Hymenochaetales & 430 & 1 & 1 & & 86 & 342 \\
\hline 刺革菌科 Hymenochaetales & 340 & 1 & & & 57 & 282 \\
\hline 新小薄孔菌科 Neoantrodiellaceae & 2 & & & & 1 & 1 \\
\hline 重担菌科 Repetobasidiaceae & 8 & & & & 2 & 6 \\
\hline 裂孔菌科 Schizoporaceae & 58 & & 1 & & 18 & 39 \\
\hline 未定科 Incertae sedis & 22 & & & & 8 & 14 \\
\hline 辐片包目 Hysterangiales & 20 & & & & 4 & 16 \\
\hline 辐片包科 Hysterangiaceae & 16 & & & & 4 & 12 \\
\hline 栓心包科 Mesophelliaceae & 1 & & & & & 1 \\
\hline 鬼笔腹菌科 Phallogastraceae & 2 & & & & & 2 \\
\hline 川普包科 Trappeaceae & 1 & & & & & 1 \\
\hline 夏氏伏革菌目 Jaapiales & 1 & & & & 1 & \\
\hline 夏氏伏革菌科 Jaapiaceae & 1 & & & & 1 & \\
\hline 鬼笔目 Phallales & 70 & 1 & & 1 & 20 & 48 \\
\hline 闭腹菌科 Claustulaceae & 3 & & & & & 3 \\
\hline 鬼笔科 Phallaceae & 67 & 1 & & 1 & 20 & 45 \\
\hline 多孔菌目 Polyporales & 1,078 & 1 & 1 & 10 & 355 & 711 \\
\hline 囊㓞革菌科 Cystostereaceae & 5 & & & & 1 & 4 \\
\hline 拟层孔菌科 Fomitopsidaceae & 146 & & & 4 & 57 & 85 \\
\hline 脆孔菌科 Fragiliporiaceae & 1 & & & & & 1 \\
\hline 灵芝科 Ganodermataceae & 129 & & & 4 & 51 & 74 \\
\hline 肉孔菌科 Meripilaceae & 21 & & & & 8 & 13 \\
\hline 干朽菌科 Meruliaceae & 156 & & & & 38 & 118 \\
\hline 原毛平革菌科 Phanerochaetaceae & 123 & & 1 & & 23 & 99 \\
\hline 多孔菌科 Polyporaceae & 478 & & & 2 & 172 & 304 \\
\hline 绣球菌科 Sparassidaceae & 6 & & & & 1 & 5 \\
\hline 刺狍齿耳菌科 Steccherinaceae & 6 & & & & 2 & 4 \\
\hline 侧担菌科 Xenasmataceae & 3 & & & & 1 & 2 \\
\hline 未定科 Incertae sedis & 4 & 1 & & & 1 & 2 \\
\hline 红菇目 Russulales & 560 & 1 & 3 & 2 & 211 & 329 \\
\hline 地花菌科 Albatrellaceae & 21 & & & & 5 & 16 \\
\hline 淀粉㓞革菌科 Amylostereaceae & 2 & & & & 2 & \\
\hline 耳匙菌科 Auriscalpiaceae & 19 & & & 1 & 8 & 10 \\
\hline 刺狍多孔菌科 Bondarzewiaceae & 37 & & & & 12 & 25 \\
\hline
\end{tabular}


表1 (续) Table 1 (continued)

\begin{tabular}{|c|c|c|c|c|c|c|}
\hline \multirow[t]{2}{*}{ 评估类群 Taxa } & \multirow{2}{*}{$\begin{array}{l}\text { 物种数 } \\
\text { No. of species }\end{array}$} & \multicolumn{5}{|c|}{ 受威胁等级及物种数 Threatened categories and number of species } \\
\hline & & $\begin{array}{l}\text { 濒危 } \\
\text { Endangered }\end{array}$ & $\begin{array}{l}\text { 易危 } \\
\text { Vulnerable }\end{array}$ & $\begin{array}{l}\text { 近危 } \\
\text { Near Threatened }\end{array}$ & $\begin{array}{l}\text { 无危 } \\
\text { Least Concern }\end{array}$ & $\begin{array}{l}\text { 数据不足 } \\
\text { Data Deficient }\end{array}$ \\
\hline 木齿菌科 Echinodontiaceae & 2 & & & & 1 & 1 \\
\hline 粘齿菌科 Gloeodontiaceae & 1 & & & & & 1 \\
\hline 猴头菌科 Hericiaceae & 12 & & 2 & & 4 & 6 \\
\hline 茸瑚菌科 Lachnocladiaceae & 16 & & & & 2 & 14 \\
\hline 隔狍伏革菌科 Peniophoraceae & 35 & & & & 1 & 34 \\
\hline 红菇科 Russulaceae & 335 & 1 & 1 & & 161 & 172 \\
\hline 冠狍革菌科 Stephanosporaceae & 4 & & & & & 4 \\
\hline 㓞革菌科 Stereaceae & 61 & & & & 12 & 49 \\
\hline 未定科 Incertae sedis & 16 & & & 1 & 3 & 12 \\
\hline 蜡壳菌目 Sebacinales & 9 & & & & 1 & 8 \\
\hline 蜡壳菌科 Sebacinaceae & 9 & & & & 1 & 8 \\
\hline 拟㓞革菌目 Stereopsidales & 6 & & & & 2 & 4 \\
\hline 拟㓞革菌科 Stereopsidaceae & 6 & & & & 2 & 4 \\
\hline 革菌目 Thelephorales & 73 & & 1 & & 15 & 57 \\
\hline 坂氏齿菌科 Bankeraceae & 36 & & & & 9 & 27 \\
\hline 革菌科 Thelephoraceae & 37 & & 1 & & 6 & 30 \\
\hline 䊁狍孔菌目 Trechisporales & 23 & & & & 1 & 22 \\
\hline 刺狍菌科 Hydnodontaceae & 23 & & & & 1 & 22 \\
\hline 胶瑚菌目 Tremellodendropsidales & 2 & & & & & 2 \\
\hline 胶瑚菌科 Tremellodendropsidaceae & 2 & & & & & 2 \\
\hline 未定目 Incertae sedis & 50 & & & & 18 & 32 \\
\hline 未定科 Incertae sedis & 50 & & & & 18 & 32 \\
\hline 花耳纲 Dacrymycetes & 52 & 2 & 1 & & 19 & 30 \\
\hline 花耳目 Dacrymycetales & 52 & 2 & 1 & & 19 & 30 \\
\hline 花耳科 Dacrymycetaceae & 52 & 2 & 1 & & 19 & 30 \\
\hline 银耳纲 Tremellomycetes & 56 & & 1 & & 19 & 36 \\
\hline 胶珊瑚目 Holtermanniales & 2 & & & & 2 & \\
\hline 胶珊瑚科 Holtermanniaceae & 2 & & & & 2 & \\
\hline 银耳目 Tremellales & 54 & & 1 & & 17 & 36 \\
\hline 布勒掷狍酵母科 Bulleraceae & 2 & & & & & 2 \\
\hline 明木耳科 Hyaloriaceae & 2 & & & & 2 & \\
\hline 白耳科 Naemateliaceae & 3 & & 1 & & & 2 \\
\hline 暗银耳科 Phaeotremellaceae & 2 & & & & 1 & 1 \\
\hline 栅菌科 Phragmoxenidiaceae & 1 & & & & & 1 \\
\hline 链担耳科 Sirobasidiaceae & 3 & & & & 2 & 1 \\
\hline 银耳科 Tremellaceae & 41 & & & & 12 & 29 \\
\hline 未定纲 Incertae sedis & 2 & & & & & 2 \\
\hline 未定目 Incertae sedis & 2 & & & & & 2 \\
\hline 未定科 Incertae sedis & 2 & & & & & 2 \\
\hline
\end{tabular}

评估结果表明, 受威胁大型担子菌共45种，占 被评估大型担子菌物种总数的 $0.72 \%$, 其中包括濒 危15种、易危 30 种(表1和表2)。近危的大型担子菌
共54种，占被评估大型担子菌总数的 $0.86 \%$ 。无危的 大型担子菌共1,918种，占被评估大型担子菌物种 总数的 $30.60 \%$ 。数据缺乏的大型担子菌共 4,251 种, 
表2 大型担子菌受威胁物种评估等级、分布及用途

Table 2 Categories, distribution and usage of the threatened species of macro-basidiomycetes

\begin{tabular}{|c|c|c|c|c|c|}
\hline $\begin{array}{l}\text { 物种 } \\
\text { Species }\end{array}$ & $\begin{array}{l}\text { 等级 } \\
\text { Categories }\end{array}$ & $\begin{array}{l}\text { 科 } \\
\text { Family }\end{array}$ & $\begin{array}{l}\text { 地理分布 } \\
\text { Distribution }\end{array}$ & $\begin{array}{l}\text { 中国特有种 } \\
\text { Endemic to China }\end{array}$ & $\begin{array}{l}\text { 用途 } \\
\text { Usage }\end{array}$ \\
\hline $\begin{array}{l}\text { 云南蘑菇 } \\
\text { Agaricus yunnanensis }\end{array}$ & $\begin{array}{l}\text { 濒危 } \\
\text { Endangered }\end{array}$ & $\begin{array}{l}\text { 蘑菇科 } \\
\text { Agaricaceae }\end{array}$ & $\begin{array}{l}\text { 中国云南、四川 } \\
\text { China: Yunnan, Sichuan }\end{array}$ & $\begin{array}{l}\text { 是 } \\
\text { Yes }\end{array}$ & \\
\hline $\begin{array}{l}\text { 阳城光黑腹菌 } \\
\text { Alpova yangchengensis }\end{array}$ & $\begin{array}{l}\text { 易危 } \\
\text { Vulnerable }\end{array}$ & $\begin{array}{l}\text { 桩菇科 } \\
\text { Paxillaceae }\end{array}$ & $\begin{array}{l}\text { 中国山西 } \\
\text { China: Shanxi }\end{array}$ & $\begin{array}{l}\text { 是 } \\
\text { Yes }\end{array}$ & \\
\hline $\begin{array}{l}\text { 线托鹅膏 } \\
\text { Amanita tomentosivolva }\end{array}$ & $\begin{array}{l}\text { 易危 } \\
\text { Vulnerable }\end{array}$ & $\begin{array}{l}\text { 我高科 } \\
\text { Amanitaceae }\end{array}$ & $\begin{array}{l}\text { 中国云南 } \\
\text { China: Yunnan }\end{array}$ & $\begin{array}{l}\text { 是 } \\
\text { Yes }\end{array}$ & \\
\hline $\begin{array}{l}\text { 小孔小薄孔菌 } \\
\text { Antrodiella micra }\end{array}$ & $\begin{array}{l}\text { 易危 } \\
\text { Vulnerable }\end{array}$ & $\begin{array}{l}\text { 原毛平革菌科 } \\
\text { Phanerochaetaceae }\end{array}$ & $\begin{array}{l}\text { 中国吉林、福建 } \\
\text { China: Jilin, Fujian }\end{array}$ & $\begin{array}{l}\text { 是 } \\
\text { Yes }\end{array}$ & \\
\hline $\begin{array}{l}\text { 橙香牛肝菌 } \\
\text { Boletus citrifragrans }\end{array}$ & $\begin{array}{l}\text { 易危 } \\
\text { Vulnerable }\end{array}$ & $\begin{array}{l}\text { 牛肝菌科 } \\
\text { Boletaceae }\end{array}$ & $\begin{array}{l}\text { 中国四川、云南、西藏; 缅甸; 泰国 } \\
\text { China: Sichuan, Yunnan, Xizang; Burma; } \\
\text { Thailand }\end{array}$ & $\begin{array}{l}\text { 否 } \\
\text { No }\end{array}$ & $\begin{array}{l}\text { 食用 } \\
\text { Edible }\end{array}$ \\
\hline $\begin{array}{l}\text { 小橙黄牛肝菌 } \\
\text { Boletus miniatoaurantiacus }\end{array}$ & $\begin{array}{l}\text { 易危 } \\
\text { Vulnerable }\end{array}$ & $\begin{array}{l}\text { 牛肝菌科 } \\
\text { Boletaceae }\end{array}$ & $\begin{array}{l}\text { 中国广东; 北美洲 } \\
\text { China: Guangdong; North America }\end{array}$ & $\begin{array}{l}\text { 否 } \\
\text { No }\end{array}$ & $\begin{array}{l}\text { 食用 } \\
\text { Edible }\end{array}$ \\
\hline $\begin{array}{l}\text { 湖南胶角耳 } \\
\text { Calocera hunanensis }\end{array}$ & $\begin{array}{l}\text { 濒危 } \\
\text { Endangered }\end{array}$ & $\begin{array}{l}\text { 花耳科 } \\
\text { Dacrymycetaceae }\end{array}$ & $\begin{array}{l}\text { 中国湖南 } \\
\text { China: Hunan }\end{array}$ & $\begin{array}{l}\text { 是 } \\
\text { Yes }\end{array}$ & \\
\hline $\begin{array}{l}\text { 莽山胶角耳 } \\
\text { Calocera mangshanensis }\end{array}$ & $\begin{array}{l}\text { 易危 } \\
\text { Vulnerable }\end{array}$ & $\begin{array}{l}\text { 花耳科 } \\
\text { Dacrymycetaceae }\end{array}$ & $\begin{array}{l}\text { 中国湖南、云南 } \\
\text { China: Hunan, Yunnan }\end{array}$ & $\begin{array}{l}\text { 是 } \\
\text { Yes }\end{array}$ & \\
\hline $\begin{array}{l}\text { 羊肚菌状胶角耳 } \\
\text { Calocera morchelloides }\end{array}$ & $\begin{array}{l}\text { 濒危 } \\
\text { Endangered }\end{array}$ & $\begin{array}{l}\text { 花耳科 } \\
\text { Dacrymycetaceae }\end{array}$ & $\begin{array}{l}\text { 中国福建 } \\
\text { China: Fujian }\end{array}$ & $\begin{array}{l}\text { 是 } \\
\text { Yes }\end{array}$ & \\
\hline $\begin{array}{l}\text { 彭氏丽口包 } \\
\text { Calostoma pengii }\end{array}$ & $\begin{array}{l}\text { 濒危 } \\
\text { Endangered }\end{array}$ & $\begin{array}{l}\text { 丽口包科 } \\
\text { Calostomataceae }\end{array}$ & $\begin{array}{l}\text { 中国湖南 } \\
\text { China: Hunan }\end{array}$ & $\begin{array}{l}\text { 是 } \\
\text { Yes }\end{array}$ & \\
\hline $\begin{array}{l}\text { 变孢丽口包 } \\
\text { Calostoma variispora }\end{array}$ & $\begin{array}{l}\text { 易危 } \\
\text { Vulnerable }\end{array}$ & $\begin{array}{l}\text { 丽口包科 } \\
\text { Calostomataceae }\end{array}$ & $\begin{array}{l}\text { 中国辽宁 } \\
\text { China: Liaoning }\end{array}$ & $\begin{array}{l}\text { 是 } \\
\text { Yes }\end{array}$ & \\
\hline $\begin{array}{l}\text { 云南丽口包 } \\
\text { Calostoma yunnanense }\end{array}$ & $\begin{array}{l}\text { 易危 } \\
\text { Vulnerable }\end{array}$ & $\begin{array}{l}\text { 丽口包科 } \\
\text { Calostomataceae }\end{array}$ & $\begin{array}{l}\text { 中国云南 } \\
\text { China: Yunnan }\end{array}$ & $\begin{array}{l}\text { 是 } \\
\text { Yes }\end{array}$ & \\
\hline $\begin{array}{l}\text { 麦黄钟伞 } \\
\text { Campanella straminea }\end{array}$ & $\begin{array}{l}\text { 濒危 } \\
\text { Endangered }\end{array}$ & $\begin{array}{l}\text { 小皮企科 } \\
\text { Marasmiaceae }\end{array}$ & $\begin{array}{l}\text { 中国云南 } \\
\text { China: Yunnan }\end{array}$ & $\begin{array}{l}\text { 是 } \\
\text { Yes }\end{array}$ & \\
\hline $\begin{array}{l}\text { 云南鸡油菌 } \\
\text { Cantharellus yunnanensis }\end{array}$ & $\begin{array}{l}\text { 易危 } \\
\text { Vulnerable }\end{array}$ & $\begin{array}{l}\text { 鸡油菌科 } \\
\text { Cantharellaceae }\end{array}$ & $\begin{array}{l}\text { 中国贵州、云南、广西 } \\
\text { China: Guizhou, Yunnan, Guangxi }\end{array}$ & $\begin{array}{l}\text { 是 } \\
\text { Yes }\end{array}$ & $\begin{array}{l}\text { 食用 } \\
\text { Edible }\end{array}$ \\
\hline $\begin{array}{l}\text { 海南笼头菌 } \\
\text { Clathrus hainanensis }\end{array}$ & $\begin{array}{l}\text { 濒危 } \\
\text { Endangered }\end{array}$ & $\begin{array}{l}\text { 鬼笔科 } \\
\text { Phallaceae }\end{array}$ & $\begin{array}{l}\text { 中国海南 } \\
\text { China: Hainan }\end{array}$ & $\begin{array}{l}\text { 是 } \\
\text { Yes }\end{array}$ & \\
\hline $\begin{array}{l}\text { 新囊靴耳 } \\
\text { Crepidotus neocystidiosus }\end{array}$ & $\begin{array}{l}\text { 濒危 } \\
\text { Endangered }\end{array}$ & $\begin{array}{l}\text { 丝盖伞科 } \\
\text { Inocybaceae }\end{array}$ & $\begin{array}{l}\text { 中国云南 } \\
\text { China: Yunnan }\end{array}$ & $\begin{array}{l}\text { 是 } \\
\text { Yes }\end{array}$ & \\
\hline $\begin{array}{l}\text { 景洪黑蛋巢菌 } \\
\text { Cyathus cheliensis }\end{array}$ & $\begin{array}{l}\text { 濒危 } \\
\text { Endangered }\end{array}$ & $\begin{array}{l}\text { 蘑菇科 } \\
\text { Agaricaceae }\end{array}$ & $\begin{array}{l}\text { 中国云南 } \\
\text { China: Yunnan }\end{array}$ & $\begin{array}{l}\text { 是 } \\
\text { Yes }\end{array}$ & \\
\hline $\begin{array}{l}\text { 紊乱黑蛋巢菌 } \\
\text { Cyathus confusus }\end{array}$ & $\begin{array}{l}\text { 濒危 } \\
\text { Endangered }\end{array}$ & $\begin{array}{l}\text { 蘑菇科 } \\
\text { Agaricaceae }\end{array}$ & $\begin{array}{l}\text { 中国宁夏、云南 } \\
\text { China: Ningxia, Yunnan }\end{array}$ & $\begin{array}{l}\text { 是 } \\
\text { Yes }\end{array}$ & \\
\hline $\begin{array}{l}\text { 五台山黑蛋巢菌 } \\
\text { Cyathus wutaishanensis }\end{array}$ & $\begin{array}{l}\text { 濒危 } \\
\text { Endangered }\end{array}$ & $\begin{array}{l}\text { 蘑菇科 } \\
\text { Agaricaceae }\end{array}$ & $\begin{array}{l}\text { 中国山西 } \\
\text { China: Shanxi }\end{array}$ & $\begin{array}{l}\text { 是 } \\
\text { Yes }\end{array}$ & \\
\hline $\begin{array}{l}\text { 小狍软齿菌 } \\
\text { Dentipellis microspora }\end{array}$ & $\begin{array}{l}\text { 易危 } \\
\text { Vulnerable }\end{array}$ & $\begin{array}{l}\text { 猴头菌科 } \\
\text { Hericiaceae }\end{array}$ & $\begin{array}{l}\text { 中国吉林 } \\
\text { China: Jilin }\end{array}$ & $\begin{array}{l}\text { 是 } \\
\text { Yes }\end{array}$ & \\
\hline $\begin{array}{l}\text { 近杯伞状粉褶草 } \\
\text { Entoloma subclitocyboides }\end{array}$ & $\begin{array}{l}\text { 易危 } \\
\text { Vulnerable }\end{array}$ & $\begin{array}{l}\text { 粉褶萆科 } \\
\text { Entolomataceae }\end{array}$ & $\begin{array}{l}\text { 中国贵州、海南、湖南 } \\
\text { China: Guizhou, Hainan, Hunan }\end{array}$ & $\begin{array}{l}\text { 是 } \\
\text { Yes }\end{array}$ & \\
\hline $\begin{array}{l}\text { 承德高腹菌 } \\
\text { Gautieria chengdensis }\end{array}$ & $\begin{array}{l}\text { 易危 } \\
\text { Vulnerable }\end{array}$ & $\begin{array}{l}\text { 钉菇科 } \\
\text { Gomphaceae }\end{array}$ & $\begin{array}{l}\text { 中国河北、湖北 } \\
\text { China: Hebei, Hubei }\end{array}$ & $\begin{array}{l}\text { 是 } \\
\text { Yes }\end{array}$ & \\
\hline $\begin{array}{l}\text { 猴头菇 } \\
\text { Hericium erinaceus }\end{array}$ & $\begin{array}{l}\text { 易危 } \\
\text { Vulnerable }\end{array}$ & $\begin{array}{l}\text { 猴头菌科 } \\
\text { Hericiaceae }\end{array}$ & $\begin{array}{l}\text { 中国黑龙江、吉林、辽宁、内蒙古、河北、 } \\
\text { 山东、甘肃、湖南、四川、贵州、云南; 日 } \\
\text { 本; 亚洲; 欧洲; 北美洲 } \\
\text { China: Heilongjiang, Jilin, Liaoning, Inner } \\
\text { Mongolia, Hebei, Shandong, Gansu, Hunan, } \\
\text { Sichuan, Guizhou, Yunnan; Japan; Asia; } \\
\text { Europe; North America }\end{array}$ & $\begin{array}{l}\text { 否 } \\
\text { No }\end{array}$ & $\begin{array}{l}\text { 食药用 } \\
\text { Edible and } \\
\text { medicinal }\end{array}$ \\
\hline
\end{tabular}


表2 (续) Table 2 (continued)

\begin{tabular}{|c|c|c|c|c|c|}
\hline $\begin{array}{l}\text { 物种 } \\
\text { Species }\end{array}$ & $\begin{array}{l}\text { 等级 } \\
\text { Categories }\end{array}$ & $\begin{array}{l}\text { 科 } \\
\text { Family }\end{array}$ & $\begin{array}{l}\text { 地理分布 } \\
\text { Distribution }\end{array}$ & $\begin{array}{l}\text { 中国特有种 } \\
\text { Endemic species }\end{array}$ & $\begin{array}{l}\text { 用途 } \\
\text { Usage }\end{array}$ \\
\hline $\begin{array}{l}\text { 斑玉䓬 } \\
\text { Hypsizygus marmoreus }\end{array}$ & $\begin{array}{l}\text { 易危 } \\
\text { Vulnerable }\end{array}$ & $\begin{array}{l}\text { 离褶伞科 } \\
\text { Lyophyllaceae }\end{array}$ & $\begin{array}{l}\text { 中国黑龙江、吉林、辽宁、河北、山西、 } \\
\text { 浙江、福建、台湾、香港; 日本; 欧洲 } \\
\text { China: Heilongjiang, Jilin, Liaoning, Hebei, } \\
\text { Shanxi, Zhejiang, Fujian, Taiwan, Hong } \\
\text { Kong; Japan; Europe }\end{array}$ & $\begin{array}{l}\text { 否 } \\
\text { No }\end{array}$ & $\begin{array}{l}\text { 食药用 } \\
\text { Edible and } \\
\text { medicinal }\end{array}$ \\
\hline $\begin{array}{l}\text { 长白乳菇 } \\
\text { Lactarius changbaiensis }\end{array}$ & $\begin{array}{l}\text { 易危 } \\
\text { Vulnerable }\end{array}$ & $\begin{array}{l}\text { 红菇科 } \\
\text { Russulaceae }\end{array}$ & $\begin{array}{l}\text { 中国吉林、云南 } \\
\text { China: Jilin, Yunnan }\end{array}$ & $\begin{array}{l}\text { 是 } \\
\text { Yes }\end{array}$ & \\
\hline $\begin{array}{l}\text { 迷你乳菇 } \\
\text { Lactarius minimus }\end{array}$ & $\begin{array}{l}\text { 濒危 } \\
\text { Endangered }\end{array}$ & $\begin{array}{l}\text { 红菇科 } \\
\text { Russulaceae }\end{array}$ & $\begin{array}{l}\text { 中国广东; 英国 } \\
\text { China: Guangdong; Britain }\end{array}$ & $\begin{array}{l}\text { 否 } \\
\text { No }\end{array}$ & \\
\hline $\begin{array}{l}\text { 中国白环蘑 } \\
\text { Leucoagaricus sinicus }\end{array}$ & $\begin{array}{l}\text { 易危 } \\
\text { Vulnerable }\end{array}$ & $\begin{array}{l}\text { 光柄菇科 } \\
\text { Pluteaceae }\end{array}$ & $\begin{array}{l}\text { 中国浙江 } \\
\text { China: Zhejiang }\end{array}$ & $\begin{array}{l}\text { 是 } \\
\text { Yes }\end{array}$ & \\
\hline $\begin{array}{l}\text { 蒙古白丽蘑 } \\
\text { Leucocalocybe mongolica }\end{array}$ & $\begin{array}{l}\text { 易危 } \\
\text { Vulnerable }\end{array}$ & $\begin{array}{l}\text { 分类位置未定 } \\
\text { Incertae sedis }\end{array}$ & $\begin{array}{l}\text { 中国黑龙江、吉林、辽宁、内蒙古、河北、 } \\
\text { 甘肃、青海、新疆; 蒙古 } \\
\text { China: Heilongjiang, Jilin, Liaoning, Inner } \\
\text { Mongolia, Hebei, Gansu, Qinghai, Xinjiang; } \\
\text { Mongolia }\end{array}$ & $\begin{array}{l}\text { 否 } \\
\text { No }\end{array}$ & $\begin{array}{l}\text { 食用 } \\
\text { Edible }\end{array}$ \\
\hline $\begin{array}{l}\text { 金耳 } \\
\text { Naematelia aurantialba }\end{array}$ & $\begin{array}{l}\text { 易危 } \\
\text { Vulnerable }\end{array}$ & $\begin{array}{l}\text { 白耳科 } \\
\text { Naemateliaceae }\end{array}$ & $\begin{array}{l}\text { 中国内蒙古、陕西、宁夏、甘肃、青海、 } \\
\text { 湖南、四川、云南、西藏 } \\
\text { China: Inner Mongolia, Shaanxi, Ningxia, } \\
\text { Gansu, Qinghai, Hunan, Sichuan, Yunnan, } \\
\text { Xizang }\end{array}$ & $\begin{array}{l}\text { 是 } \\
\text { Yes }\end{array}$ & $\begin{array}{l}\text { 食药用 } \\
\text { Edible and } \\
\text { medicinal }\end{array}$ \\
\hline $\begin{array}{l}\text { 疏褶暗金钱菌 } \\
\text { Phaeocollybia sparsilamellae }\end{array}$ & $\begin{array}{l}\text { 濒危 } \\
\text { Endangered }\end{array}$ & $\begin{array}{l}\text { 丝膜菌科 } \\
\text { Cortinariaceae }\end{array}$ & $\begin{array}{l}\text { 中国云南 } \\
\text { China: Yunnan }\end{array}$ & $\begin{array}{l}\text { 是 } \\
\text { Yes }\end{array}$ & \\
\hline $\begin{array}{l}\text { 云南多舌菌 } \\
\text { Pyrrhoglossum yunnanense }\end{array}$ & $\begin{array}{l}\text { 易危 } \\
\text { Vulnerable }\end{array}$ & $\begin{array}{l}\text { 丝膜菌科 } \\
\text { Cortinariaceae }\end{array}$ & $\begin{array}{l}\text { 中国云南 } \\
\text { China: Yunnan }\end{array}$ & $\begin{array}{l}\text { 是 } \\
\text { Yes }\end{array}$ & \\
\hline $\begin{array}{l}\text { 短狍枝瑚菌 } \\
\text { Ramaria nanispora }\end{array}$ & $\begin{array}{l}\text { 易危 } \\
\text { Vulnerable }\end{array}$ & $\begin{array}{l}\text { 钉菇科 } \\
\text { Gomphaceae }\end{array}$ & $\begin{array}{l}\text { 中国云南 } \\
\text { China: Yunnan }\end{array}$ & $\begin{array}{l}\text { 是 } \\
\text { Yes }\end{array}$ & \\
\hline $\begin{array}{l}\text { 拟粉红枝瑚菌 } \\
\text { Ramaria neoformosa }\end{array}$ & $\begin{array}{l}\text { 易危 } \\
\text { Vulnerable }\end{array}$ & $\begin{array}{l}\text { 钉菇科 } \\
\text { Gomphaceae }\end{array}$ & $\begin{array}{l}\text { 中国青海、四川、云南; 意大利 } \\
\text { China: Qinghai, Sichuan, Yunnan; Italy }\end{array}$ & $\begin{array}{l}\text { 否 } \\
\text { No }\end{array}$ & \\
\hline $\begin{array}{l}\text { 朱细枝瑚菌 } \\
\text { Ramaria rubriattenuipes }\end{array}$ & $\begin{array}{l}\text { 易危 } \\
\text { Vulnerable }\end{array}$ & $\begin{array}{l}\text { 钉菇科 } \\
\text { Gomphaceae }\end{array}$ & $\begin{array}{l}\text { 中国云南 } \\
\text { China: Yunnan }\end{array}$ & $\begin{array}{l}\text { 是 } \\
\text { Yes }\end{array}$ & $\begin{array}{l}\text { 食用 } \\
\text { Edible }\end{array}$ \\
\hline $\begin{array}{l}\text { 红肉枝瑚菌 } \\
\text { Ramaria rubricarnata }\end{array}$ & $\begin{array}{l}\text { 易危 } \\
\text { Vulnerable }\end{array}$ & $\begin{array}{l}\text { 钉菇科 } \\
\text { Gomphaceae }\end{array}$ & $\begin{array}{l}\text { 中国云南; 美国 } \\
\text { China: Yunnan; USA }\end{array}$ & $\begin{array}{l}\text { 否 } \\
\text { No }\end{array}$ & \\
\hline $\begin{array}{l}\text { 牛樟芝 } \\
\text { Taiwanofungus camphoratus }\end{array}$ & $\begin{array}{l}\text { 濒危 } \\
\text { Endangered }\end{array}$ & $\begin{array}{l}\text { 分类位置未定 } \\
\text { Incertae sedis }\end{array}$ & $\begin{array}{l}\text { 中国台湾 } \\
\text { China: Taiwan }\end{array}$ & $\begin{array}{l}\text { 是 } \\
\text { Yes }\end{array}$ & $\begin{array}{l}\text { 药用 } \\
\text { Medicinal }\end{array}$ \\
\hline $\begin{array}{l}\text { 端圆蚁巢伞 } \\
\text { Termitomyces tylerianus }\end{array}$ & $\begin{array}{l}\text { 易危 } \\
\text { Vulnerable }\end{array}$ & $\begin{array}{l}\text { 离褶伞科 } \\
\text { Lyophyllaceae }\end{array}$ & $\begin{array}{l}\text { 中国湖南、四川、云南、西藏、广东; 非洲 } \\
\text { China: Hunan, Sichuan, Yunnan, Xizang, } \\
\text { Guangdong; Africa }\end{array}$ & $\begin{array}{l}\text { 否 } \\
\text { No }\end{array}$ & $\begin{array}{l}\text { 食用 } \\
\text { Edible }\end{array}$ \\
\hline $\begin{array}{l}\text { 干巴菌 } \\
\text { Thelephora ganbajun }\end{array}$ & $\begin{array}{l}\text { 易危 } \\
\text { Vulnerable }\end{array}$ & $\begin{array}{l}\text { 革菌科 } \\
\text { Thelephoraceae }\end{array}$ & $\begin{array}{l}\text { 中国甘肃、河南、安徽、江西、四川、云 } \\
\text { 南、西藏、广东、广西 } \\
\text { China: Gansu, Henan, Anhui, Jiangxi, Si- } \\
\text { chuan, Yunnan, Xizang, Guangdong, Guangxi }\end{array}$ & $\begin{array}{l}\text { 是 } \\
\text { Yes }\end{array}$ & $\begin{array}{l}\text { 食用 } \\
\text { Edible }\end{array}$ \\
\hline $\begin{array}{l}\text { 松口蘑 } \\
\text { Tricholoma matsutake }\end{array}$ & $\begin{array}{l}\text { 易危 } \\
\text { Vulnerable }\end{array}$ & $\begin{array}{l}\text { 口蘑科 } \\
\text { Tricholomataceae }\end{array}$ & $\begin{array}{l}\text { 中国黑龙江、吉林、辽宁、内蒙古、山西、 } \\
\text { 陕西、甘肃、青海、湖北、四川、贵州、 } \\
\text { 云南、西藏、广西; 日本; 欧洲 } \\
\text { China: Heilongjiang, Jilin, Liaoning, Inner } \\
\text { Mongolia, Shanxi, Shaanxi, Gansu, Qinghai, } \\
\text { Hubei, Sichuan, Guizhou, Yunnan, Xizang, } \\
\text { Guangxi; Japan; Europe }\end{array}$ & $\begin{array}{l}\text { 否 } \\
\text { No }\end{array}$ & $\begin{array}{l}\text { 食药用 } \\
\text { Edible and } \\
\text { medicinal }\end{array}$ \\
\hline
\end{tabular}


表2 (续) Table 2 (continued)

\begin{tabular}{|c|c|c|c|c|c|}
\hline $\begin{array}{l}\text { 物种 } \\
\text { Species }\end{array}$ & $\begin{array}{l}\text { 等级 } \\
\text { Categories }\end{array}$ & $\begin{array}{l}\text { 科 } \\
\text { Family }\end{array}$ & $\begin{array}{l}\text { 地理分布 } \\
\text { Distribution }\end{array}$ & $\begin{array}{l}\text { 中国特有种 } \\
\text { Endemic species }\end{array}$ & $\begin{array}{l}\text { 用途 } \\
\text { Usage }\end{array}$ \\
\hline 青盖拟口蘑 & 易危 & 蘑菇科 & 中国山西、甘肃、四川 & 是 & \\
\hline 变孢柄灰包 & 濒危 & 蘑菇科 & 中国内蒙古; 蒙古 & 否 & \\
\hline Tulostoma variisporum & Endangered & Agaricaceae & China: Inner Mongolia; Mongolia & No & \\
\hline 榆林柄灰包 & 易危 & 蘑菇科 & 中国内蒙古、陕西 & 是 & \\
\hline Tulostoma yulinense & Vulnerable & Agaricaceae & China: Inner Mongolia, Shaanxi & Yes & \\
\hline 冬小包脚菇 & 易危 & 蘑菇科 & 中国贵州 & 是 & \\
\hline Volvariella brumalis & Vulnerable & Agaricaceae & China: Guizhou & Yes & \\
\hline
\end{tabular}

占被评估大型担子菌物种总数的 $67.82 \%$ 。我国需要 关注和保护的大型担子菌达4,350种, 占被评估大 型担子菌物种总数的 $69.40 \%$ 。

本次评估的蘑菇纲有 13 种濒危、28种易危、54 种近危、1,880种无危、4,183种数据不足, 受威胁物 种数占该纲被评估物种总数的 $0.67 \%$ 。花耳纲有 2 种 濒危、 1 种易危、19种无危、 30 种数据不足, 受威胁 物种数量占该纲被评估物种总数的 $5.77 \%$ 。银耳纲 有1种易危、19种无危、36种数据不足, 受威胁物种 数量占该纲被评估物种总数的 $1.79 \%$ (表1)。

\section{2 各评估等级物种概况}

\subsection{1 濒危}

濒危的大型担子菌共15种(表2), 其中, 牛樟芝 和斜生纤孔菌(Inonotus obliquus, 原称“桦褐孔菌”) 为药用菌。牛樟芝分布在我国台湾地区, 目前已经 可以人工栽培, 但其野外种群受人类采挖利用的影 响极为严重, 几乎无成熟子实体存在, 物种的生存 状况十分堪忧。斜生纤孔菌的分布范围相对较广, 但人类的过度采挖使其生存状况受到严重威胁。此 外, 濒危的大型担子菌中有紊乱黑蛋巢菌(Cyathus confusus)、云南蘑菇(Agaricus yunnanensis)等12个中 国特有种。紊乱黑蛋巢菌的分布区域狭小, 种群数 量有限, 目前仅保存一份采自云南昆明的模式标 本。尽管有报道它在其他地区也有分布, 但缺乏可 靠的标本证据。受人类活动及气候变化的影响, 该 物种的生存受到威胁, 处于濒危状态。景洪黑蛋巢 菌(Cyathus cheliensis)和五台山黑蛋巢菌(C. wutaishanensis)与紊乱黑蛋巢菌的情况类似, 分布范围狭 窄, 易受人类活动及气候变化的影响, 为濒危物 种。其余10种濒危担子菌除云南磨菇在云南、四川 两地分布以外, 其余物种已知的分布范围均局限在 一个省, 报道的分布点极少, 种群数量有限, 易受
人类活动以及气候变化等的影响, 因此评为濒危。

\subsection{2 易危}

易危的大型担子菌包括松口蘑、金耳(Naematelia aurantialba)、湖南胶角耳(Calocera hunane$n s i s) 、$ 莽山胶角耳(C. mangshanensis)和羊肚菌状胶 角耳(C. morchelloides) 等30种。松口蘑是一种名贵 的野生食用菌, 具有很高的经济价值, 大量出口日 本。松口蘑除了在日本四岛和朝鲜半岛有分布外, 在中国主要形成“藏东南-横断山区”和“大兴安岭长白山”两大分布区。然而, 在西南和东北主产区的 大部分地区, 松口蘑是当地百姓的重要经济来源, 过度采挖现象并未得到有效遏制。虽然它的分布范 围相对较广, 种群密度和生物量也较大, 但目前种 群密度已大幅下降, 达到易危等级。

受威胁的食药用大型担子菌共13种, 其中猴头 菇(或称“猴头菌”)、斑玉草(Hypsizygus marmoreus)、 金耳、松口蘑等可以食药两用(表2)。这些物种中, 松 口蘑、橙香牛肝菌(Boletus citrifragrans)、牛肝菌、 云南鸡油菌 (Cantharellus yunnanensis)、干巴菌 (Thelephora ganbajun, 或称 “干巴革菌”) 等目前仍 无法人工栽培, 其开发和利用主要依赖野生资源。 部分种类虽已经开始规模化栽培, 但野生资源仍然 显著衰减, 面临着严重威胁。以牛樟芝为例, 这种 药用真菌仅分布在台湾, 野生子实体价格极其昂贵, 虽然已经人工培植, 但自然种群分布区狭窄, 野生 资源受到极为严重的破坏, 很难在野外再找到成熟 的子实体, 物种已经处于濒危状态。此外, 猴头菇 野生种群也受到严重威胁, 但因其分布区域较广, 种群数量相对较大, 处于易危状态。

\subsection{3 近危}

近危的大型担子菌共54种, 分布在蘑菇属( Agaricus)、假芝属(Amauroderma)、牛肝菌属(Boletus)、 
鸡油菌属(Cantharellus)、灵芝属(Ganoderma)、侧耳 属(Pleurotus)、枝瑚菌属(Ramaria)、蚁巢伞属等28 个属, 其中枝瑚菌属物种最多, 达 16 种; 蚁巢伞属 次之, 有 5 种。这些物种大多数具有一定的食药用价 值, 因而受到人类活动影响较严重, 但由于地理分 布相对广泛, 种群数量相对较多, 资源较为丰富, 处于近危等级。此外, 块菌、蚁巢伞、灵芝等一些 物种种群开始出现衰退的迹象, 如不合理控制采挖 量和采挖方式, 并采取一定的保护措施, 这些物种 很可能在不远的将来陷入受威胁状态。

\section{3 受威胁物种的地理分布}

大型担子菌受威胁物种在各省(区、市)的分布 不均匀。云南省是受威胁大型担子菌分布最为集中 的省份, 受威胁物种多达22种, 占受威胁大型担子 菌物种总数的近 $1 / 2$; 其次为四川 10 种，吉林 9 种; 此外, 内蒙古和湖南各7种，黑龙江和甘肃各6种, 辽宁、山西、青海和贵州各5种，河北、陕西、西藏 和广东各 4 种, 福建和广西各3种, 宁夏、新疆、浙 西和香港各1种(表2)。可见我国西南和东北是受威 胁大型担子菌分布相对集中的地区，应重点关注。

在 45 种受威胁的大型担子菌中, 有32种是中国 特有种，占受威胁大型担子菌物种总数的 $71.11 \%$, 高于地衣型真菌和大型子囊菌受威胁物种中的特 有种比例。在受威胁的中国特有种中, 目前16种在 云南有报道，占受威胁特有种的 $50 \%$ 。此外，四川、 湖南、贵州等省也有多种受威胁的中国特有大型担 子菌分布。

\section{4 大型担子菌受威胁因素分析}

大型担子菌的受威胁因素与子囊菌类似, 很多 分布狭窄的中国特有种, 如云南蘑菇、线托我膏 (Amanita tomentosivolva)、湖南胶角耳、麦黄钟伞 (Campanella straminea)、海南笼头菌(Clathrus hainanensis)、云南多舌菌(Pyrrhoglossum yunnanense) 等, 不仅分布区域局限, 而且种群数量少、子实体发 生频率低。全球气候变化和人类活动导致的栖息地 缩小和破坏是威胁这些物种生存的重要因素。本次 评估中, 受威胁大型担子菌物种中食药用菌比例达 $1 / 3$ 以上。对于一些目前尚无法人工栽培的重要野生 食药用菌来说, 过度采挖是导致这些物种受到威胁 的主要原因。受经济利益的驱动, 松口蘑的采挖大部 分在子实体成熟之前, 孢子还来不及散发, 导致土壤

中的菌源得不到有效补充，加剧了其受威胁程度。

\section{5 物种评估实例}

\subsection{1 蒙古白丽蘑 Leucocalocybe mongolica (S.} Imai) X. D. Yu \& Y. J. Yao Afr. J. Microbiol. Res. 5(31): 5751 (2011) (图1)

形态特征：菌盖直径1.5-17 cm, 幼时菌盖边缘 内卷, 成熟后渐平展, 表面奶油色带黄色调, 光滑。 菌褶弯生, 宽2.0-4.0 mm, 近白色, 密, 具小菌褶。 菌柄长2.0-9 cm，直径1.5-4 cm，基部稍膨大，表面 近白色, 中实。菌肉致密, 白色, 厚1.0-2.0 cm。孢 子印白色。味道鲜美，有香气。孢子7.0-9.5 × 5.0-6.0 $\mu \mathrm{m}, \mathrm{Q}=1.21$, 近陏圆形, 薄壁, 表面有微小突起, 近透明，非淀粉质。担子棒状，具四个孢子梗。菌 髓菌丝规则, 所有的菌丝具有锁状联合。

模式产地: 蒙古。

地理分布: 中国黑龙江、吉林、辽宁、内蒙古、 河北、甘肃、青海、新疆; 蒙古。

研究标本: 内蒙古：赤峰，克什克滕旗，白音 敖包国家级自然保护区，4 IX 2018，魏铁铮，彭泽 文，庄剑云和刘铁志, 8794, HMAS 281506; 锡林浩 特，锡林郭勒盟，西乌珠穆沁旗，草地上， $21 \mathrm{X}$ 2017，于晓丹, SYAU-FUNGI-17244; 呼伦贝尔, 陈 巴尔虎旗，草地上， 7 IX 2017，于晓丹，SYAUFUNGI-17209; 河北: 张北草原, 草地上, VIII 1987, Tian Shao-yi \& Gao Shi-jin, HMAS 60305。

评估等级及依据：易危Vulnerable, C1。

讨论：蒙古白丽蘑的主要特征是子实体粗壮, 菌盖边缘常内卷，具有香气，是中国北方名贵的野 生食用菌。这是由日本菌物学家Imai (1938)最早报 道的，由于该种具有口蘑状的子实体，因此最初将

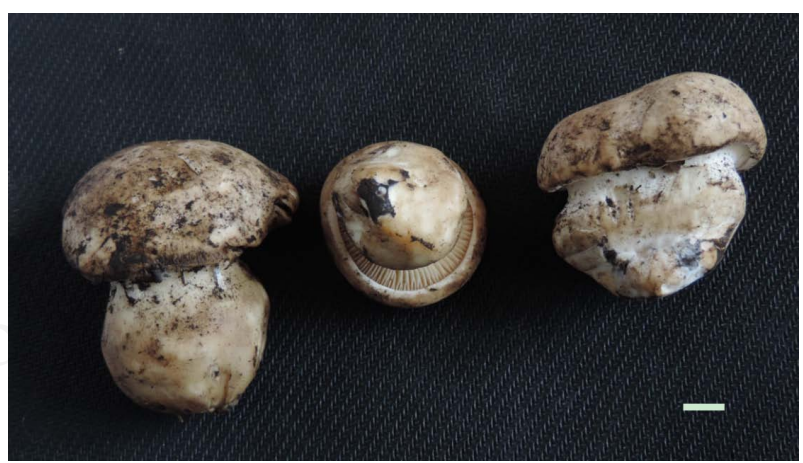

图1 蒙古白丽蘑, SYAU-FUNGI-17209。标尺: 1 cm。 Fig. 1 Leucocalocybe mongolica, SYAU-FUNGI-17209. Bar, $1 \mathrm{~cm}$. 
其归入口蘑属(Tricholoma)。后来，于晓丹等(2011) 基于nLSU序列片段的分析结果以及该种的腐生特 征明显不同于其他外生菌根菌口蘑属种类的特征, 将其从口蘑属中独立出来, 并以该种为模式种成立 新属白丽蘑属(Leucocalocybe X. D. Yu and Y. J. Yao, gen. nov.), 目前蒙古白丽蘑是该属的唯一成 员。后来的研究结果也证实了该种的分类地位(董冬 和图力古尔, 2013)。

生存状况：蒙古白丽蘑主要分布在我国内蒙 古、河北北部地区草原上(邓叔群, 1963; 卯晓岚, 2000; 李玉等, 2015), 俗称白磨、大白蘑等, 味道鲜 美，深受人们的喜爱，是我国北方草原盛产的“口 蘑”中的上品(卯晓岗，2000)，田绍义和杨发茂(1992) 报道成功驯化栽培蒙古口蘑, 但缺乏人工栽培后续 报道, 其开发利用仍只能依靠野生资源, 因此导致 野生蒙古白丽蘑的售价一路攀升，最高达到1,600 元 $/ \mathrm{kg}$ 。随着市场需求的增加, 以及近年来的草原退 化、过度采挖等原因, 该种在草原的生态环境被破 坏严重, 分布范围减少(董冬, 2013 ${ }^{\circledR}$; 鲁铁, 2018), 在评估中认为该种产量持续下降了至少 $10 \%$, 达到 了易危等级。而且目前的研究结果发现该种的野生 资源遗传多样性水平较低(鲁铁, 2018), 生境被大量 片断化，生存环境亟需得到有效保护。

保护建议：加强物种资源调查，摸清家底，针 对集中分布区域和生境破坏区域建立自然保护区， 开展人工保育工作。各级政府和相关部门应建立和 完善物种保护的相关法规, 从根源上制止过度采挖 和栖息地破坏等各种不良现象，从根本上扭转种群 不断下降的局面。

\subsection{2 松口蘑 Tricholoma matsutake (S. Ito \& S.} Imai) Singer, Annls mycol. 41(1/3): 77 (1943) (图2)

形态特征: 子实体口磨状, 菌盖直径6-25 cm, 幼时呈子弹头状, 后渐平展, 中央稍突起, 表面黄 褐色, 中间褐色, 边缘颜色渐浅, 表面被黄褐色纤 维状鳞片。菌褶弯生, 宽 2-4 mm, 近白色, 密, 具小 菌褶。菌柄长 $10-20 \mathrm{~cm}$, 直径 $1.5-3 \mathrm{~cm}$, 圆柱形, 与 菌盖同色，具有相似鳞片。具有白色菌环，位于菌 柄上部。菌肉厚, 致密, 近白色, 味鲜美, 有浓郁香 气。孢子6.5-7.5 × 5.5-6.5 $\mu \mathrm{m}, \mathrm{Q}=1.16$, 宽椭圆形,

(1) 董冬 (2013) 蒙古白丽蘑资源及其遗传多样性研究. 硕士学位论文, 吉林农业大学, 长春.

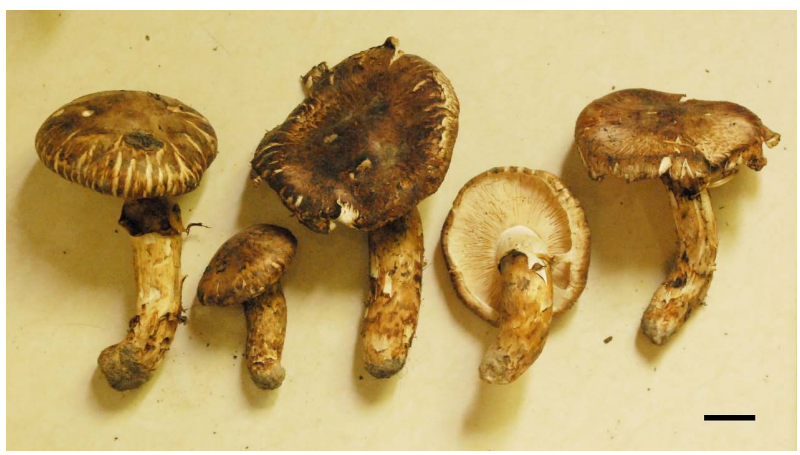

图2 松口蘑, HMAS251027。标尺: 1 cm。

Fig. 2 Tricholoma matsutake, HMAS251027. Bar, $1 \mathrm{~cm}$.

薄壁，透明，非淀粉质。担子棒状，具四个孢子梗。 菌髓菌丝规则, 无锁状联合。

模式产地：日本。

地理分布: 中国黑龙江、吉林、辽宁、内蒙古、 山西、陕西、甘肃、青海、湖北、四川、贵州、云 南、广西; 日本。

研究标本: 中国: 西藏, 波密县, 26 VII 2010, 魏铁铮1548, HMAS 251027; 四川, 阿坝州, 小金县 美沃乡双河村干沟，松栎混交林中松树根下, 9 VIII 2003, 邓晖, DH 309, HMAS 96669; 凉山州, 德昌 县巴洞乡团结九队, 16 VIII 2003, 邓晖和姚一建, DH 362, HMAS 96530; 楚雄, 紫溪山茶花园附近山 上 2,500 m, 13 VIII 2004, DH 561, HMAS 96563; 辽宁：丹东，栎树林, 10 IX 2018, 郭洪波, SYAUFUNGI-18031。

评估等级及依据：易危Vulnerable, B2ab(ii)。

讨论：松口蘑, 俗称松茸, 该种主要特征是子 实体呈黄褐色，具有浓郁的香气，松口蘑喜与松、 杉、栎等树种形成外生菌根菌。群生或散生，或形 成蘑菇圈，子实体形态上易与俊松口蘑(Tricholoma bakamatsutake)相混淆，但件松口蘑的子实体稍小， 而且分布范围更广, 子实层具有明显的囊状体结构 (邓晖等, 2003)。

生存状况：在中国, 松口蘑主要分布在两大地 区，即“藏东南-横断山区”和“大兴安岭-长白山”, 其中“藏东南-横断山区”地区包括云南、四川(中国 科学院青藏高原综合科学考察队, 1996)、西藏 (中国 科学院青藏高原综合科学考察队, 1983)、甘肃 (卯晓 岗和庄剑云, 1997), “大兴安岭-长白山”地区包括黑 龙江、吉林、辽宁(李玉等, 2015)、内蒙古(图力古 
尔，2016)。此外，曾经还有松口蘑分布于台湾、福 建(上海农业科学院食用菌研究所, 1991; 卯晓岗, 2000)的报道, 但缺乏标本的印证; 后来的研究认为 在这两个地区没有松口蘑的分布(李玉等, 2015)。松 口蘑具有极高的经济价值，在国内的分布地区多， 种群密度和生物量较大, 但由于该种的巨大食用价 值, 加上至今无法实现人工栽培, 导致该种的野生 资源被人类长期过度采挖, 致使种群密度持续下降; 并且栖息地质量下降, 种群占有面积、分布范围减 少, 其生境破坏程度和分布面积已经达到了易危等 级的评估标准。目前, 松口蘑已被列入国家二级保 护物种, 并且在吉林省延边朝鲜族自治州龙井境内 的天佛指山建立了以松口蘑为主要保护对象的国 家级自然保护区。

保护建议: 针对该物种的保护措施已有一定成 效, 但面对日益扩大的市场需求, 仍需进一步加大 人工保育力度。加强该种资源的调查工作, 明确其 分布和种群数量, 建立长期野外监测体系, 评估其 种群的变化, 在采集区进行科普宣传, 指导采集者 合理采挖和利用。

\section{4 我国未来大型担子菌资源的评估与展望}

当前, 气候变化、人类活动干扰和过度利用对 各类大型担子菌及其栖息地存在着普遍的威胁, 因 此迫切需要全面掌握我国大型担子菌受威胁状况, 为制定和实施有效的保护措施提供科学依据。然而, 我国超过 $67 \%$ 的已报道大型担子菌物种相关数据缺 乏, 成为该类真菌物种受威胁程度评估面临的难题, 原因在于资源调查、分类和生物多样性研究不足。 为推进大型担子菌受威胁物种评估工作, 亟需深入 开展包括大型担子菌在内的我国真菌资源的普查 和编目工作，摸清其物种多样性及资源现状。以往 大部分相关的文献报道缺乏标本引证, 给后续的分 类研究、物种核对和数据整理造成很大困难。近年 来, 形态学和分子系统学手段相结合的方法已在真 菌分类研究中得到广泛应用。在未来的资源与多样 性调查中, 应重视和加强标本等凭证材料的收集和 保存, 特征性基因序列的测定, 以及物种相关信息 数据的收集和整理工作。此外, 对于大型担子菌的 重要类群, 尤其是那些物种资源比较丰富的目和科, 应重点加强系统学及生物多样性的研究。

\section{参考文献}

Alexopoulos CJ, Mims CW, Blackwell M (1996) Introductory Mycology, 4th edn. John Wiley \& Sons, Inc., New York.

Bau T (2016) List of agarics and boletoid fungi from Eastern Inner Mongolia (II). Journal of Fungal Research, 14(1), 8-21. (in Chinese with English abstract) [图力古尔 (2016) 内蒙古东部伞菌和牛肝菌名录(续). 菌物研究, 14(1), 8-21.]

Comprehensive Scientific Expedition to Qinghai-Tibet Plateau, Academia Sinica (1983) Fungi of Xizang. Science Press, Beijing. (in Chinese) [中国科学院青藏高原综合科学考察 队 (1983) 西藏真菌. 科学出版社, 北京.]

Comprehensive Scientific Expedition to Qinghai-Tibet Plateau, Academia Sinica (1996) Fungi of the Hengduan Mountains. Science Press, Beijing. (in Chinese) [中国科学院青藏高原 综合科学考察队 (1996) 横断山区真菌. 科学出版社, 北 京.]

Dai YC (2003) Rare and threatened polypores in the ecosystem of Changbaishan Nature Reserve of northeastern China. Chinese Journal of Applied Ecology, 14, 1015-1018. (in Chinese with English abstract) [戴玉成 (2003) 长白山森 林生态系统中的稀有和濒危多孔菌. 应用生态学报, 14, 1015-1018.]

Dai YC, Cui BK, Yuan HS, Wei YL (2010) A red list of polypores in China. Mycosystema, 29, 164-171. (in Chinese with English abstract) [戴玉成, 崔宝凯, 袁海生, 魏玉莲 (2010) 中国濒危的多孔菌. 菌物学报, 29, 164-171.]

Deng H, Cao ZM, Yao YJ (2003) Research on Tricholoma bakamatsutake in China. Mycosystema, 22, 132-136. (in Chinese) [邓晖, 曹哲明, 姚一建 (2003) 中国俊松口蘑研 究概况. 菌物系统, 22, 132-136.]

Dong D, Bau T (2013) A study on the taxonomic position of Tricholoma mongolicum. Journal of Fungal Research, 11(3), 172-175. (in Chinese with English abstract) [董冬, 图力古 尔 (2013) 蒙古口蘑分类地位研究. 菌物研究, 11(3), 172-175.]

Edible Fungi Research Institute of Shanghai Academy of Agricultural Sciences (1991) Edible Fungal Flora of China. China Forestry Publishing House, Beijing. (in Chinese) [上 海农业科学院食用菌研究所 (1991) 中国食用菌志. 中 国林业出版社, 北京.]

Fan YG, Bau T (2008) Quantity evaluation on priority conservation of macrofungi in Changbai Mountain Nature Reserve. Journal of Northeast Forestry University, 36(11), 86-87, 91. (in Chinese with English abstract) [范宇光, 图力古尔 (2008) 长白山自然保护区大型真菌物种优先保护的量化 评价. 东北林业大学学报, 36(11), 86-87, 91.]

Fang R, Kirk P, Wei JC, Li Y, Cai L, Fan L, Wei TZ, Zhao RL, Wang K, Yang ZL, Li TH, Li Y, Phuru-Dorji, Yao YJ (2018) Country focus: China. In: Status of the World Fungi (ed. Willis KJ), pp. 48-55. Royal Botanic Gardens, Kew.

Gyosheva M, Fakirova V, Denchev C (2000) Red list and 
threat status of Bulgarian macromycetes. Historia Naturalis Bulgarica, 11, 139-145.

Imai S (1938) On an edible Mongolian fungus "pai-mo-ku”. Proceedings of the Imperial Academy (Tokyo), 13, 280282.

IUCN (2012a) Guidelines for Application of IUCN Red List Criteria at Regional and National Levels: Version 4.0. IUCN, Gland, Switzerland \& Cambridge, UK.

IUCN (2012b) IUCN Red List Categories and Criteria: Version 3.1. 2nd edn. IUCN, Gland, Switzerland \& Cambridge, UK.

IUCN Standards and Petitions Subcommittee (2016) Guidelines for Using the IUCN Red List Categories and Criteria. Version 12. http://www.iucnredlist.org/documents/RedList Guidelines.pdf/. (accessed on 2017-09-07).

Li Y, Li TH, Yang ZL, Bau T, Dai YC (2015) Atlas of Chinese Macrofungal Resources. Central China Farmer's Publishing House, Zhengzhou. (in Chinese) [李玉, 李泰辉, 杨祝良, 图力古尔, 戴玉成 (2015) 中国大型菌物资源图鉴. 中原 农民出版社, 郑州.]

Liao YJ, Yu FF, Liu ZY, Xie DM (2008) The biodiversity, conservation and sustainable utilization of macrofungi resources in the Jinfo Mountain Nature Reserve in Chongqing. Ecological Science, 27(1), 42-45. (in Chinese with English abstract) [廖宇静, 于飞飞, 刘正宇, 谢德明(2008) 重庆金佛 山自然保护区大型真菌多样性及资源保护与可持续利用. 生态科学, 27(1), 42-45.]

Liu PG, Wang XH, Yu FQ, Zheng HD, Chen J (2003) Key taxa of larger member in higher fungi of biodiversity from China. Acta Botanica Yunnanica, 25, 285-296. (in Chinese with English abstract) [刘培贵, 王向华, 于富强, 郑焕娣, 陈娟 (2003) 中国大型高等真菌生物多样性的关键类群. 云南 植物研究, 25, 285-296.]

Lu T (2018) Genetic Diversity and Conservation Science of Leucocalocybe mongolicum. PhD dissertation, Jilin Agricultural University, Changchun. (in Chinese with English abstract) [鲁铁 (2018) 蒙古白丽蘑的遗传多样性及其保育学 研究. 博士学位论文, 吉林农业大学, 长春.]

Mao XL (2000) The Macrogungi in China. Henan Science and Technology Press, Zhengzhou. (in Chinese] [卯晓岗 (2000) 中国大型真菌. 河南科学技术出版社, 郑州.]

Mao XL, Zhuang JY (1997) Fungi of the Qinling Mountains. China Agricultural Science and Technology Press, Beijing. (in Chinese) [卯晓岗, 庄剑云 (1997) 秦岭真菌. 中国农 业科技出版社, 北京.]

Mueller GM, Schmit JP, Leacock PR, Buyck B, Cifuentes J,
Desjardin DE, Halling RE, Hjorstam K, Iturriaga T, Larsson KH, Lodge DJ, May TW, Minter D, Rajchenberg M, Redhead SA, Ryvarden L, Trappe JM, Watling R, Wu QX (2007) Global diversity and distribution of macrofungi. Biodiversity Conservation, 16, 37-48.

Senn-Irlet B, Heilmann-Clausen J, Genney D, Dahlberg A (2007) Guidance for Conservation of Macrofungi in Europe. ECCF, Strasbourg.

Singer R (1986) The Agaricales in Modern Taxonomy, 4th edn. Koeltz Scientific Books, Keonigstein.

Teng SC (1963) Fungi of China. Science Press, Beijing. (in Chinese) [邓叔群 (1963) 中国的真菌. 科学出版社, 北 京.]

Tian SY, Yang FM (1992) Domestication and cultivation of Tricholoma mongolicum. Mycosystema, 11, 146-149. (in Chinese with English abstract) [田绍义, 杨发茂 (1992) 蒙 古口蘑驯化栽培成功. 真菌学报, 11, 146-149.]

Wang JR, Liu Y, Bau T (2015) Evaluation of endangered status and conservation priority of macrofungi in Shandong Province, China. Acta Ecologica Sinica, 35, 837-848. (in Chinese with English abstract) [王建瑞, 刘宇, 图力古尔 (2015) 山东省大型真菌物种濒危程度与优先保育评价. 生态学报, 35, 837-848.]

Wang K, Liu DM, Cai L, Wu HJ, Li Y, Wei TZ, Wang YH, Wu HM, Wei XD, Li BB, Li JS, Yao YJ (2020) Methods and procedures of the red list assessment of macrofungi in China. Biodiversity Science, 28, 11-19. (in Chinese with English abstract) [王科, 刘冬梅, 蔡蕾, 吴海军, 李熠, 魏 铁铮, 王永会, 吴红梅, 卫晓丹, 李斌斌, 李俊生, 姚一 建 (2020) 中国大型真菌红色名录评估方法和程序. 生 物多样性, 28, 11-19.]

Wei TZ, Yao YJ (2010) Fungi diversity and conservation in China - a preliminary red list of macrofungi. In: Abstrast of the 9th Biodiversity Conservation and Sustainable Use Symposium (ed. Chinese National Committee for DIVERSITAS), 94-95. China Meteorological Press, Beijing. (in Chinese) [魏铁铮, 姚一建 (2010) 中国菌物多样性保护一大型 真菌初步红色名录. 见: 第九届生物多样性保护与持续 利用研讨会论文摘要集(国际生物多样性计划中国委员会 编), 94-95页.]

Yu XD, Deng H, Yao YJ (2011) Leucocalocybe, a new genus for Tricholoma mongolicum in Agaricales (Basidiomycota). African Journal of Microbiology Research, 5, 5750-5756.

(责任编委: 陈双林 责任编辑: 黄祥忠) 